\title{
ENGINEERING DESIGN IN THE PRESENCE OF WAVE GROUPS
}

\author{
Thomas D Shand ${ }^{1}$, William L. Peirson ${ }^{1}$ and Ronald J. Cox ${ }^{1}$
}

\begin{abstract}
Determining the largest wave height, $H$ which can occur in water of depth, $d$ without breaking is a fundamental reference quantity for the design of coastal structures. Current design guidelines, used to predict the ratio of breaking height to depth $\left(H_{b} / d\right)$, also known as the breaker index, are based on investigations which predominantly used monochromatic waves, thereby implicitly neglecting group effects. Groupiness or height modulation in wave trains is an inherent characteristic of freely propagating waves in deep water and has been shown within previous studies to induce breaker indices substantially exceeding those predicted by design guidelines. Additionally, the raw data upon which present design guidelines have been based exhibit considerable scatter. This scatter is surprising given the monochromatic and uniform nature of the laboratory waves.
\end{abstract}

A physical investigation at the Water Research Laboratory using new techniques for data extraction and visualisation has yielded new insights into the shoaling and breaking processes of regular and grouped waves and revealed deficiencies in the present design techniques. Monochromatic waves trains were found to develop amplitude modulation with distance along the flume due to non-linear instabilities. These instabilities are well recognized in deep-water waves and contribute to group development and the occurrence of low-probability extreme waves. These modulations induced variation in breaking wave heights, locations and derived breaker indices. Such modulation of initially regular wave trains is proposed as a possible cause of the scatter observed in raw laboratory breaker index data.

Wave group testing has revealed evolutionary cycles in local energy density during deep water propagation and that the spatial phasing of this evolution with the initiation of shoaling yielded considerably different shoaling and breaking regimes. Critically, smaller waves within the group, particularly those occurring at the front of the wave group were, at times, able to propagate into shallower water before breaking than is presently predicted by existing design guides. Causes for this discrepancy, including differences in definitions of water level and depth are investigated. However, discrepancies between observed and predicted values are found to remain. Revision to present design guidelines to directly incorporate non-linear group effects and group-induced water level variation are presented.

Keywords: wave breaking, wave group, infragravity wave, breaker index, optical surface detection

\section{INTRODUCTION}

Determining the largest wave height, $H$, which can occur in water of depth, $d$, without breaking, is a fundamental and important reference quantity for the design of coastal structures. For example, the unit mass of rock armour specified by design codes based on the Hudson formula (USACE, 2003) exhibits a wave height cubed dependency.

The ratio of breaking height $\left(H_{b}\right)$ to depth $\left(H_{b} / d\right)$, is known as the breaker index and has been the subject of much research over the past 150 years. Critical studies have been those of Goda (1970) and Weggel (1972), upon which current design guidelines (Goda, 2000; USACE, 2003) are based. The raw data, upon which present design guidelines are based, exhibit however, considerable scatter (Figure 1). This scatter is surprising given that, in the absence of turbulent perturbations, monochromatic waves should always break consistently in the same manner and in the same location.

Current design guidelines are based on investigations which predominantly used monochromatic waves, thereby neglecting group effects. Groupiness or height modulation in wavetrains is an inherent characteristic of freely propagating waves in deep water (Benjamin and Feir, 1967).

Wave groupiness has been shown to cause variation in derived breaker indices, with individual waves exhibiting different indices dependent on their position within the group (Svendsen, 2001) or spatial phasing of group evolution during shoaling (Shand et al, 2008). This group evolution, described in deep water within Banner and Peirson (2007) is the result of modulations in local energy density. Shand et al (2008) systematically investigated the influence of these modulations during shoaling by incrementally shifted a sloping bed along-flume thus altering the spatial phasing of group evolution at the initiation of shoaling. This resulted in differences in observed wave breaking positions, heights and breaker indices within the groups.

The effect of wave groupiness on engineering design is recognised with the Coastal Engineering Manual (USACE, 2003) stating that wave grouping and its consequences is of significant concern. However, there is little guidance and few practical formulae for use in practical engineering. The manual suggests that practitioners should be aware of the existence of groupiness and evaluate its

\footnotetext{
${ }^{1}$ Water Research Laboratory, School of Civil and Environmental Engineering, University of New South Wales, Sydney, Australia.
} 
importance in situations known to be sensitive to group-related phenomena although procedures for this evaluation are stated as beyond the scope of the Manual.

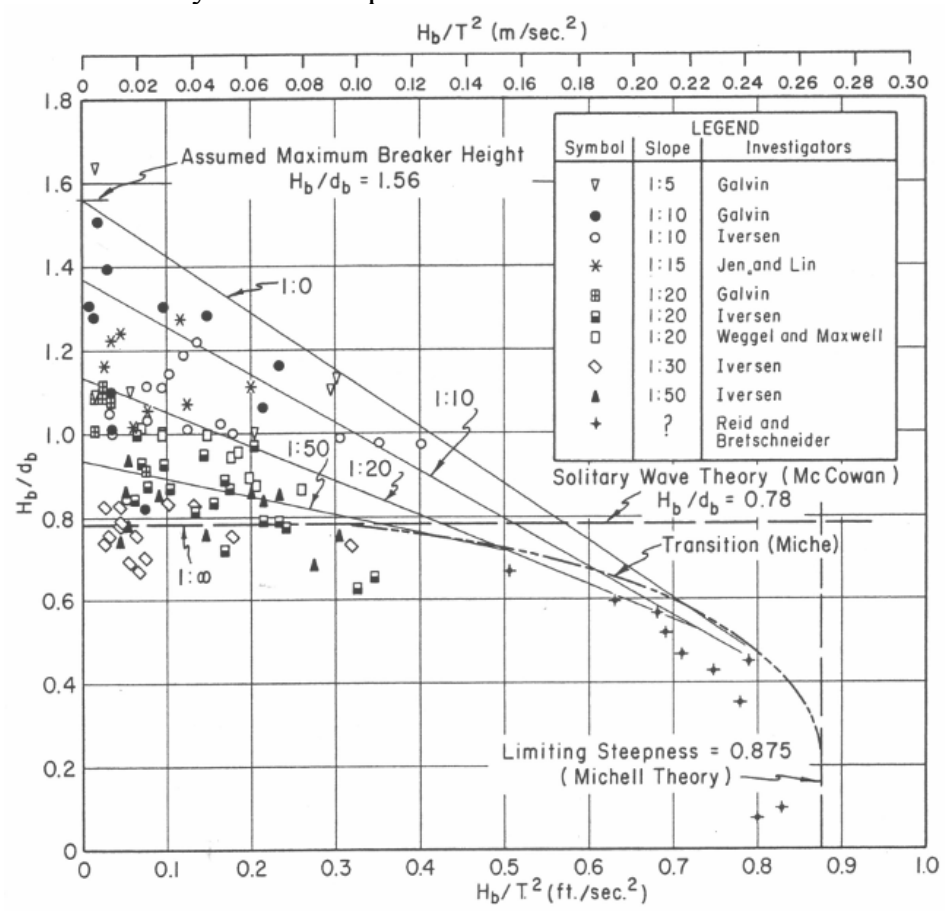

Figure 1. $H_{b} / d_{b}$ ratios as a function of wave steepness and bed slope. Curves of best fit form the basis of modern design guidelines. (Weggel, 1972).

In deep water, wave groups are also known to be accompanied by low-frequency modulations in water level (Munk 1949). Longuet-Higgins and Stewart (1962; 1964) proposed a theoretical solution to describe the local depression in water level (ste down) that occurs beneath larger waves within a group due to variations in radiation stress. Nielsen and Baldock (2010) present a shallow water solution which includes the Gaussian-shaped radiation stress forcing and leads to the И-shaped long wave (Figure 2) frequently observed within experimental data (i.e. Baldock, 2006). As group waves shoal and break, these low-frequency modulations appear to increase in amplitude and become released from the the group, subsequently propagating as free long waves (Ruessink,1998).

Groupiness in wave trains has been shown to result in variation in observed breaker indices compared to values predicted by design guidelines. Similarly, wave groups may induce temporal variations in water level and local water depths. A more though investigation of the relationship between these characteristics is undertaken and recommendations for improvement of existing predictive techniques is provided.

\section{METHODOLOGY}

\section{Testing Facilities}

A laboratory investigation has been carried out at the Water Research Laboratory (WRL) in Manly Vale, Sydney. A wave tank was used with dimensions of $30 \mathrm{~m}$ in length by $0.6 \mathrm{~m}$ in width and $0.9 \mathrm{~m}$ in height. The tank has a solid bed, glass sidewalls and incorporates a synthetic absorption beach comprised of a perforated sloping bed and horsehair beach (Figure 2).

A flexible, cantilevered plate, fixed near the base of the tank is used to generate waves within the flume (Banner and Peirson, 2007). The paddle is fronted by a synthetic damping mat to reduce high frequency secondary waves and is driven by a servo-controlled actuator. This setup allows wave group structures to be generated with excellent short and long-term stability.

An adjustable plywood bed was constructed to facilitate wave shoaling and depth-limited breaking. This bed was free-moving in the horizontal axis, along the wave tank and so could be positioned at any location relative to the evolution of the wave group to an accuracy of approximately $5 \mathrm{~mm}$. The bed was truncated at the still water level to reduce long wave reflection and the accumulation of free long wave energy within the experimental region. Free long wave energy within the experimental region was found to be less than $0.2 \%$ of peak spectral energy. 


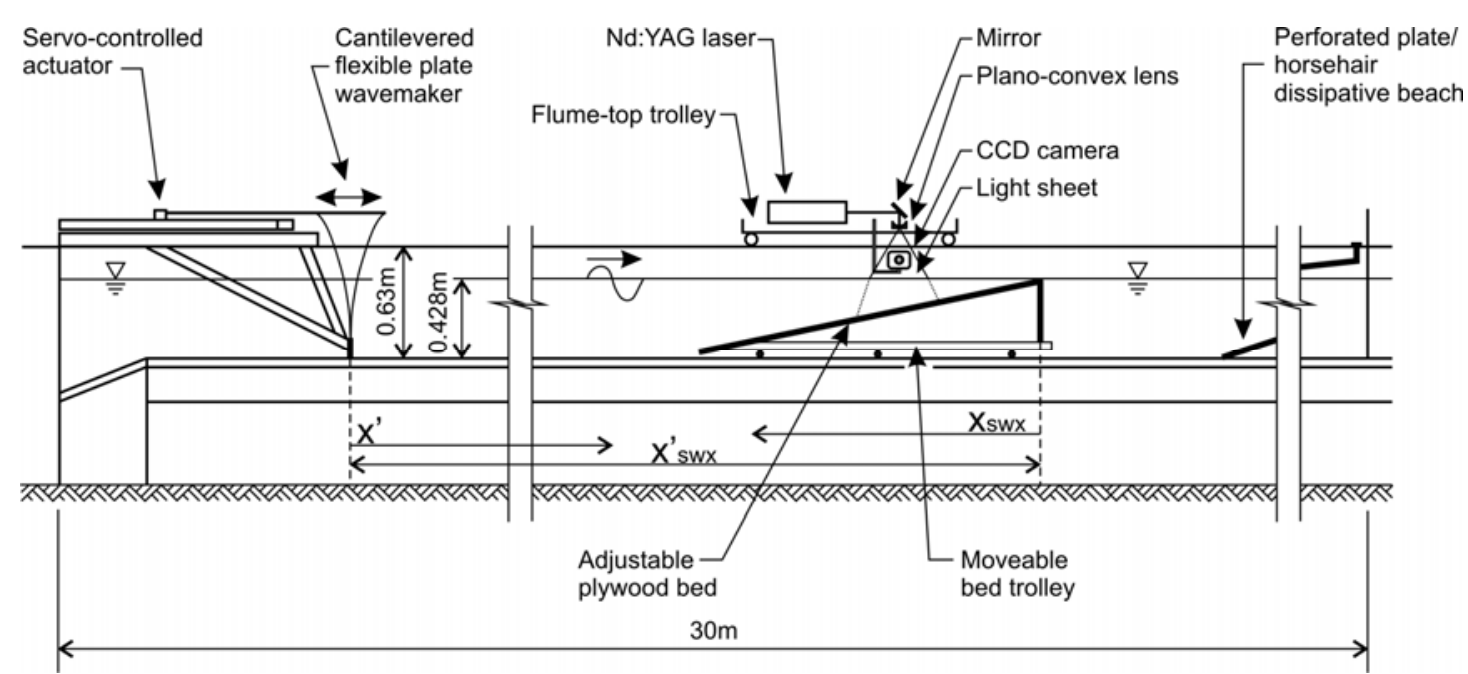

Figure 2. Schematic diagram of the experimental setup and reference notation.

\section{Optical Technique}

Traditional methods of wave measurement within laboratory environments include acoustic and capacitance or resistance probes. However, both methods are subject to significant limitations when measuring highly curved surfaces and steep waveforms within the rapidly evolving breaking and surf zones. Furthermore, both types of instrument provide only discrete spatial point measurements. An optical technique was therefore developed to capture the water surface position continually during wave shoaling, breaking and within the surf zone.

A pulsed light sheet, orientated along and in the centre of the tank is produced by a high powered Nd:YAG laser system and plano-concave lens to form a light sheet approximately $3 \mathrm{~mm}$ by $120 \mathrm{~mm}$ along the tank centre line. The water is dosed with Rhodamine WT fluorescent dye and, once excited by the laser pulse, a sharp optical interface at the free-surface can be viewed obliquely.

A CCD camera is positioned outside the tank and slightly above the free surface ensuring the meniscus did not obscure the view of the laser sheet during any phases of wave-cycle. The 2D freesurface is captured over a length of approximately $100 \mathrm{~mm}$ before the camera and laser, mounted on a trolley, is redeployed along the tank and the process repeated.

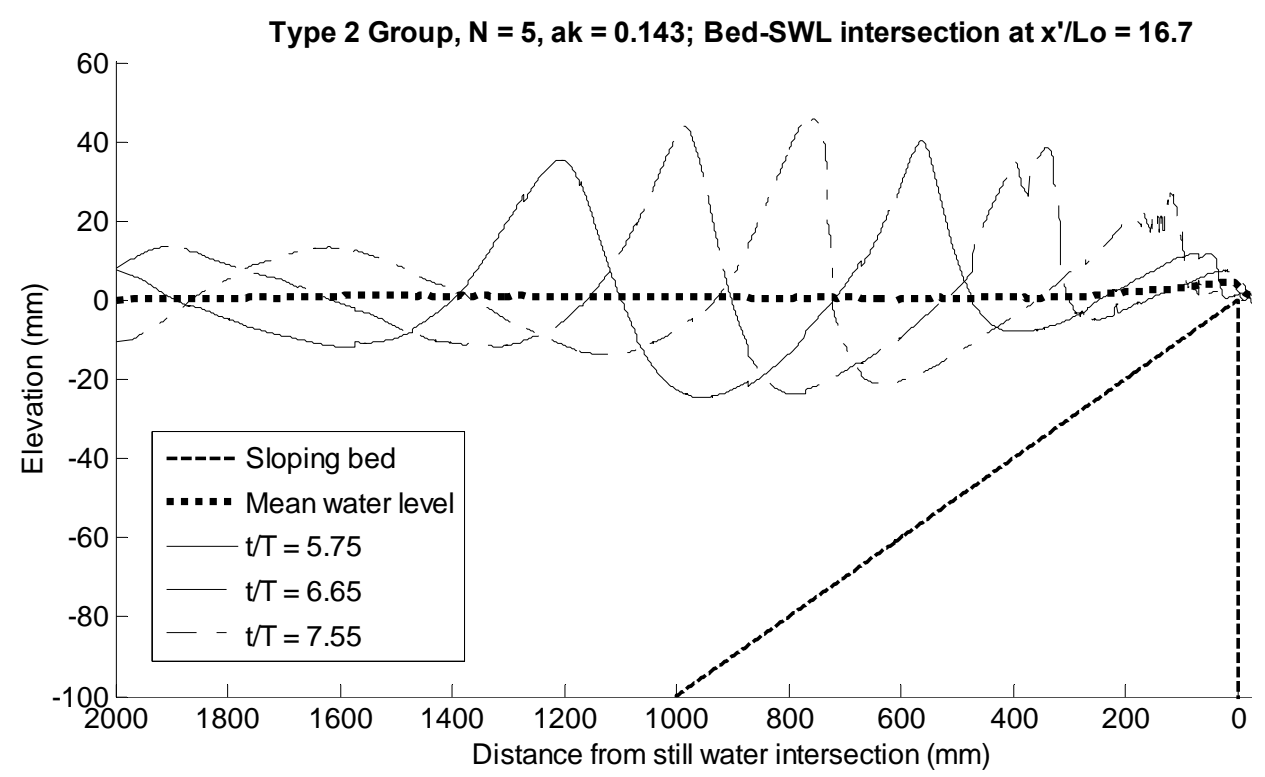

Figure 3. Examples of surface profile obtained by combining individual video records.

The surface is then detected using a two-stage algorithm to firstly exclude spurious splashes, reflections or intensity dropout and secondly, to determine the surface position using the intensity gradient. Corrections are applied for camera lens and perspective distortions and for laser sheet 
geometric variations. Surface resolution is found to 0.2 pixels $(0.05 \mathrm{~mm})$ with accuracy estimated at \pm 0.45 pixels $(0.11 \mathrm{~mm})$. Comparison to capacitance probes in deepwater show agreement within $2 \%$ in measured wave heights. Individual records are then phase-synchronised and combined to give complete 2D spatial records of surface elevation along the flume centreline (Figure 3).

\section{Testing Regime}

Three different monochromatic and four wave group structures were tested. The monochromatic waves varied in steepness $\left(s_{0}\right)$ based on their deep water amplitude $\left(a_{0}\right)$ and wave number $\left(k_{0}\right)$, with a steep, moderate and low structure tested. The wave groups varied in their generation mechanism (Case), the number of waves within the group $(N)$, and the initial wave steepness $\left(s_{0}=a_{0} k_{0}\right)$ leading to either recurrent or breaking conditions. A summary of the parameters used to generate each of these wave configurations is presented in Table 1.

\begin{tabular}{|c|c|c|c|c|c|}
\hline Wave config. & $\begin{array}{l}\text { Group } \\
\text { Case }^{1}\end{array}$ & $\begin{array}{l}\text { No. of waves } \\
\text { in group }(N)\end{array}$ & $\begin{array}{l}\text { Initial wave } \\
\text { number }\left(k_{0}\right)\end{array}$ & $\begin{array}{c}\text { Initial mean wave } \\
\text { amp. } a_{0}(\mathrm{~m})\end{array}$ & $\begin{array}{c}\text { Initial wave } \\
s_{0}=(a k)_{0}\end{array}$ \\
\hline Mono - Low & - & - & 7.4178 & 0.0149 & 0.11 \\
\hline Mono - Mod & - & - & 7.4178 & 0.0301 & 0.22 \\
\hline Mono - Steep & - & - & 7.4178 & 0.0392 & 0.29 \\
\hline $\mathrm{C} 2 \mathrm{~N} 5 \mathrm{r}$ & 2 & 5 & 7.4178 & 0.0193 & 0.143 \\
\hline C2N5sb & 2 & 5 & 7.4178 & 0.0216 & 0.16 \\
\hline $\mathrm{C} 2 \mathrm{~N} 3 \mathrm{r}$ & 2 & 3 & 7.4178 & 0.0226 & 0.168 \\
\hline C3N5 & 3 & 5 & 6.8068 & 0.0184 & 0.125 \\
\hline
\end{tabular}

\section{MONOCHROMATIC TESTING}

\section{Wave-Train Modulation}

During the propagation of monochromatic waves within deep water, the development of amplitude modulation became evident, although it was more pronounced for waves of steeper initial structure. Figure 4 depicts the surface elevation and wave height of the $s_{0}=0.29$ steepness wave at varying along-flume positions. Note the rapid and pronounced development of amplitude modulation (up to $30 \% H_{\text {mean }}$ by $k_{0} x=85$ ).

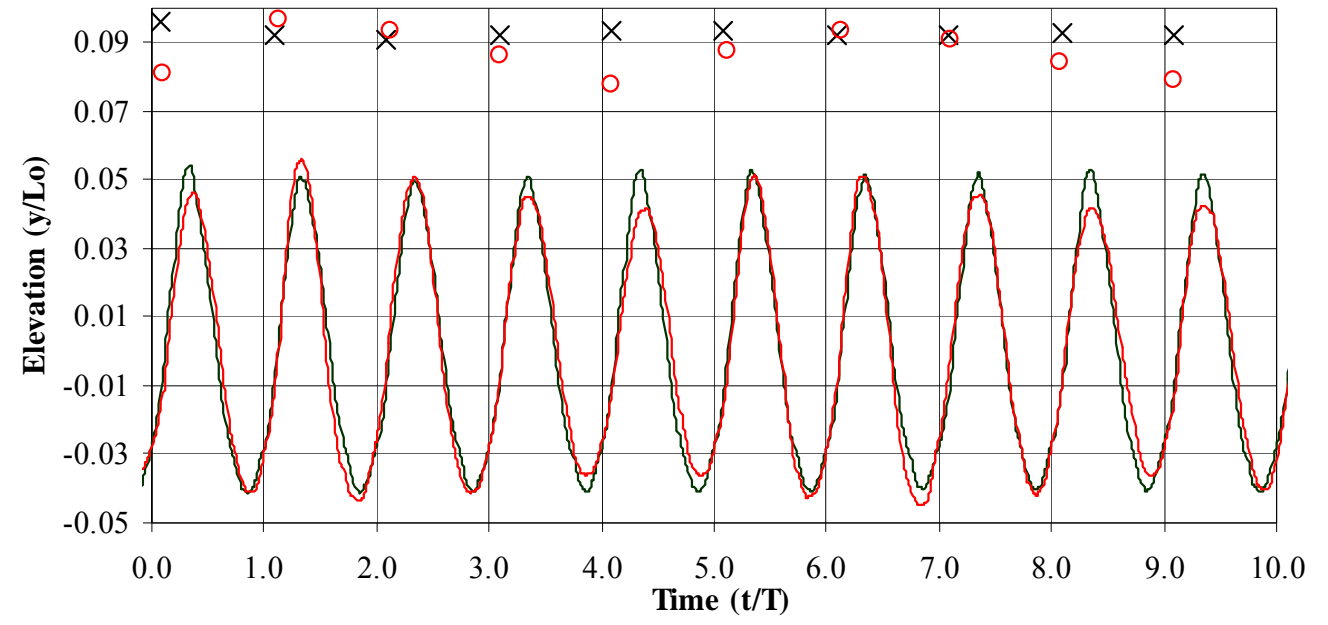

Figure 4. Surface profile and wave height for the steep $\left(s_{0}=0.29\right)$ monochromatic structure at $k_{0} X=75(y=$ $\longrightarrow$; $H=x ;$ spectra $=\longrightarrow)$ and $85(y=-; H=\circ$; spectra $=\longrightarrow)$.

\section{Breaker Index}

To define the largest wave which may occur in water of finite depth, the engineering practitioner typically uses established design guidelines such as the Coastal Engineering Manual (USACE, 2003) 
and Random Seas and Design of Maritime Structures (Goda, 2000). These guidelines use design curves derived from original studies by Weggel (1972) and Goda (1970) and may be defined by Eq. 1 and 2 respectively.

$$
\begin{gathered}
\frac{H_{b}}{d_{b}}=b-a \frac{H_{b}}{g T^{2}} \\
\frac{H_{b}}{d_{b}}=\frac{A}{d_{b} / L_{0}}\left\{1-\exp \left[-1.5 \pi \frac{d_{b}}{L_{0}}\left(1+11 s^{4 / 3}\right)\right]\right\}
\end{gathered}
$$

where $a$ and $b$ for Weggel's Eq. 1 is given by $a=43.8\left(1-\mathrm{e}^{-19 \tan \beta}\right)$ and $b=1.56 /\left(1+\mathrm{e}^{-19.5 \tan \beta}\right)$ and $A$ for Goda's Eq. 2 is 0.17 for regular waves; $H_{b}$ is the breaking wave height; $d_{b}$ the depth at breaking; $L_{0}$ is deepwater wavelength and $\mathrm{s}$, the bed slope.

A

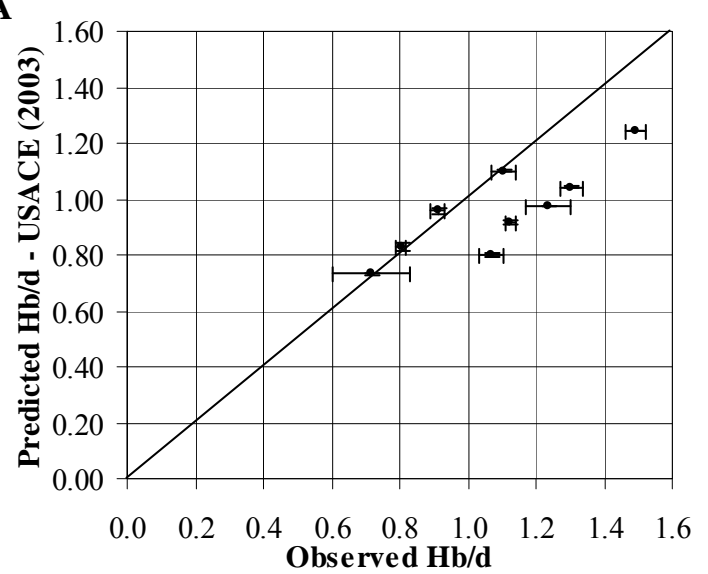

B

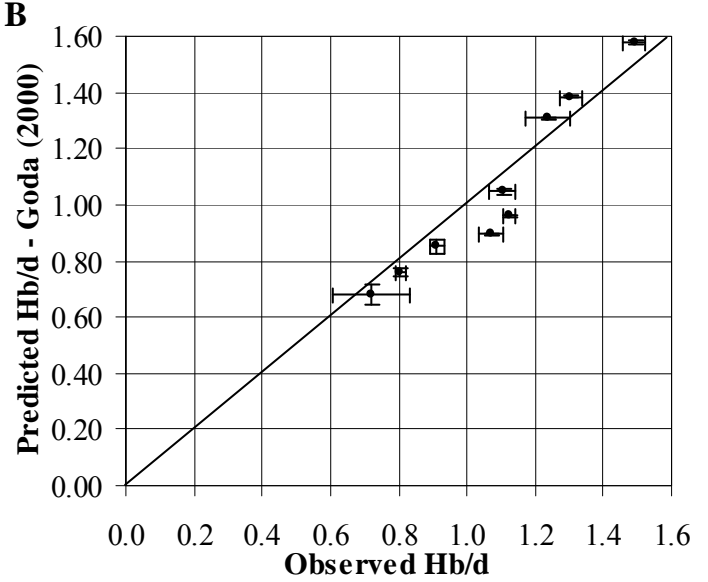

Figure 5. Observed breaker depth indices compared to that predicted by USACE (2003) (A) and Goda (2000) (B). Range in both the observed and predicted values are depicted by error bars in the both the $x$ and $y$ directions respectively. The solid line depicts an idealised relationship.

The modulation described above caused variation in wave breaking position due to differing wave heights and non-linear energy exchanges associated with modulated wave trains (Banner and Peirson, 2007). The range of wave breaking positions and heights was recorded and used to calculate breaker indices.

Observed values are compared to those predicted by design guideline formula for the three monochromatic cases on three differing bed slopes, with results presented within Figure 5. Results showed the USACE (2003) guidelines to under-predict breaker indices on steeper 5:1 and 10:1 slopes (by -17 to $-25 \%$ ) but to be in better agreement on the lower 20:1 slope, with an over-prediction by guidelines of 2 to $5 \%$. Values predicted by Goda (2000) were in better general agreement, slightly under-predicting the 10:1 and 20:1 slope values (by -5 to $-15 \%$ ) and over-predicting the steeper, 5:1 values $(+6 \%)$.

\section{WAVE GROUPS}

\section{Design with Depth Based on Still Water Level}

Breaker depth indices with depth based on still water level for the three largest waves within a C2N5r-type group breaking on a 10:1 slope for 10 differing group evolutionary phasings are presented as a function of depth within Figure 6. These observed breaker indices are compared to those predicted by design guidelines. While the waves breaking in deepest water typically remain below design guidelines values, waves breaking within the mid to inner surf zone $\left(d / L_{0}<0.05\right)$ can be observed to substantially (by up to $90 \%$ ) exceed design predicted values. 


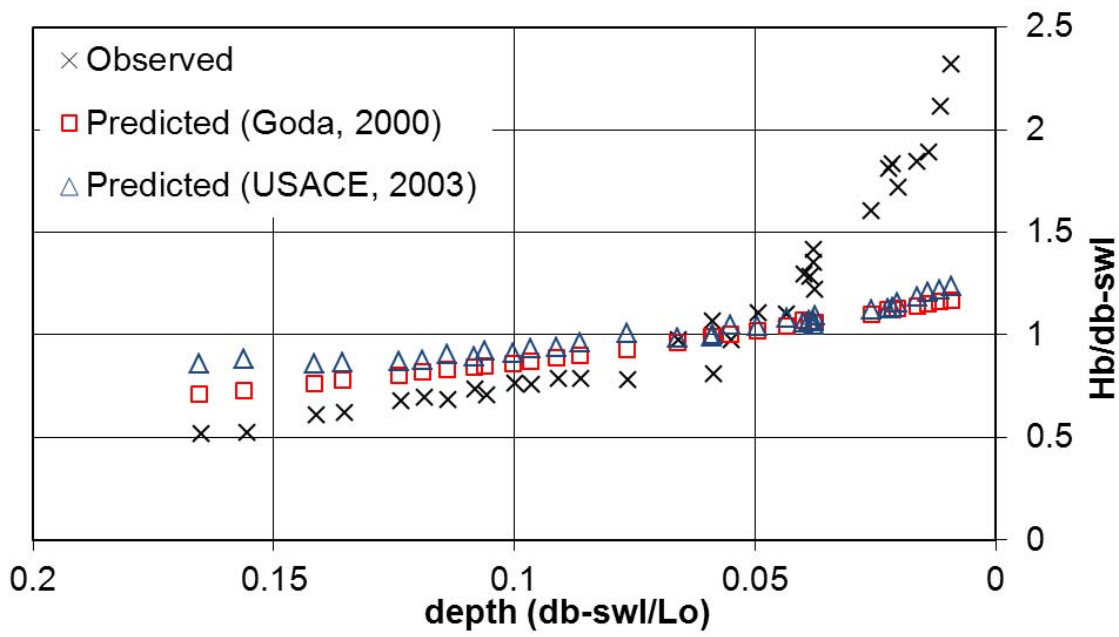

Figure 6. Breaker depth index, with depth based on still water level $\left(H_{b} / d_{s w l}\right)$ for the three largest waves of a C2N5r-type wave group breaking on an incrementally adjusted 10:1 sloping bed with values predicted by design guidelines (USACE, 2003; Goda, 2000) also provided for comparison. Note that the coefficient $A$ within the Goda expression (Eq. 2) is assumed at 0.17 .

\section{Effect of Alternative Definitions of Depth}

As evident from the above discussion, breaker indices derived from regular wave testing provide a reasonable approximation of larger waves breaking at the outer edge of the surf zone but provide a poor prediction of breaker indices within the surf zone. This is likely due to increases in water depth within the surf zone, thereby allowing larger waves to propagate into shallower water before breaking. These increases are not allowed for with depth defined according to still water level.

Goda (2000) recommends that for irregular wave breaking, where wave breaking may occur over a wide area within the surf zone, various contributors to water level must be allowed for. These include changes to the mean water level due to set down and set up and temporal changes to the water level through surf beat, or low-frequency fluctuations (i.e. Figure 7).

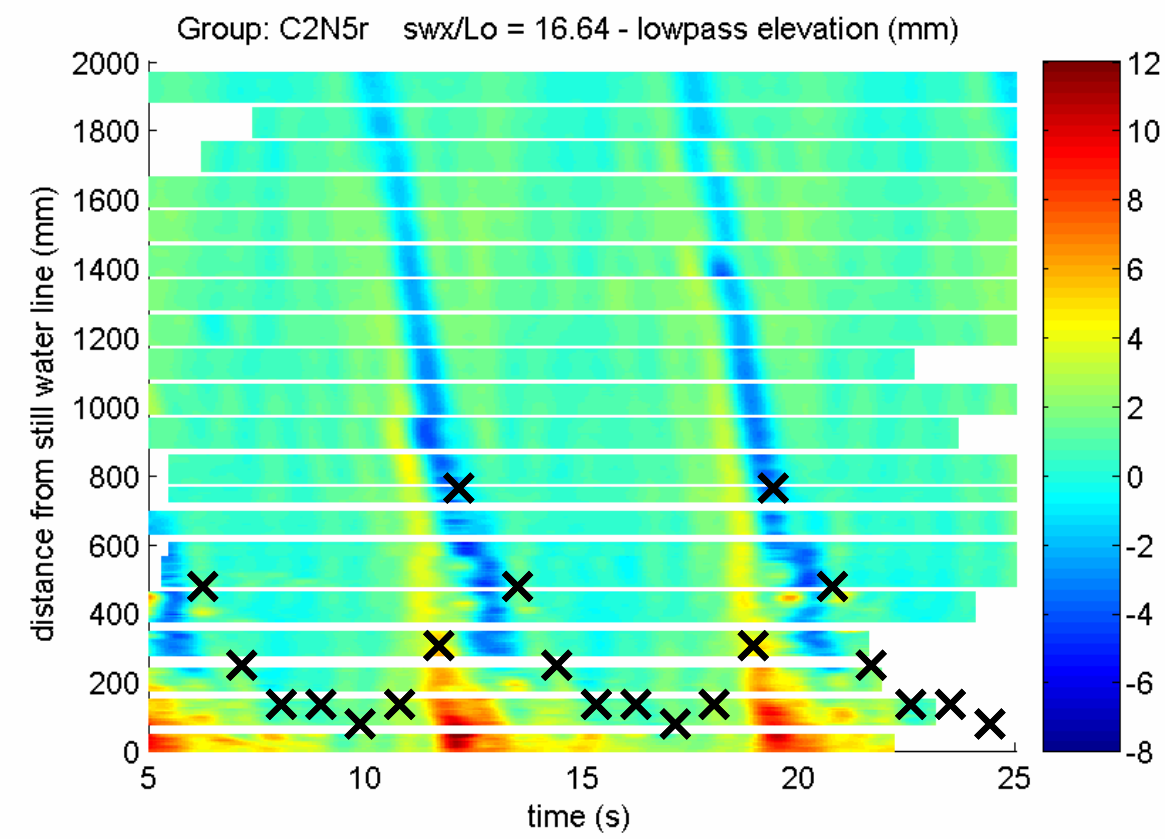

Figure 7. Space-time plot of the low-frequency surface elevation $(\mathrm{mm})$ associated with wave group propagation onto a steep (1:10), plane sloped beach. Superimposed are the break points $(x)$ of individual waves within the group.

While these differences in definition of depth would not significantly influence results in regular wave testing where wave breaking occurs in a relatively consistent location, they may cause significant 
variation in irregular or particularly grouped wave testing. Alternative definitions of depth are therefore considered in order to examine the discrepancy between observed and predicted values. These alternative definitions are used to recalculate observed breaker indices and these recalculated values compared to predicted values.

Figure 8 presents the observed wave breaker index values as shown within Figure 6, but with depth based on still water level $\left(H_{b} / d_{s w l}\right)$, mean water level (including the effect of set up - $\left.H_{b} / d_{m w l}\right)$ and the effective surface elevation at the time of wave passage (depth at the time and position of wave breaking $-H_{b} / d_{e f f}$.

While the definition of depth does not appear to markedly affect the derived breaker index for larger waves, breaking in the outer surf zone, it causes significant variation in smaller waves breaking within the mid to inner surf zone. Similarly, while the guidelines predict reasonably the breaker index in the outer surf zone, they remain non-conservative, at least during some phase of group evolution, within the inner surf zone, regardless of depth definition (Table 2). This implies that for design in the presence of wave groups, even if the contribution of set up and/or temporal variation associated with long waves are calculated and included within the assumed depth, some under-prediction of breaking wave height is likely to result.

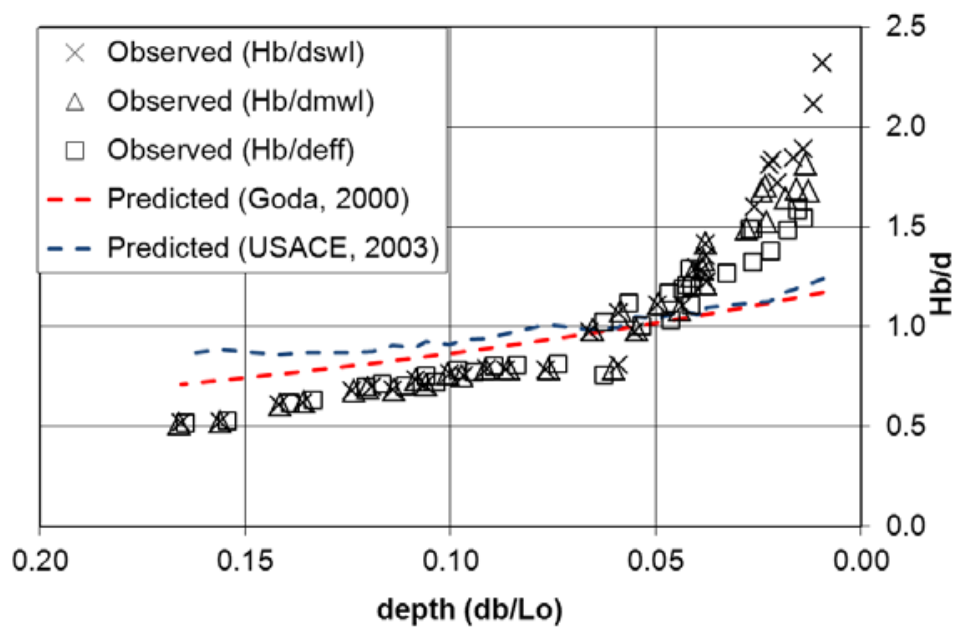

Figure 8. Observed wave breaker index values for differing definitions of depth compared to guidelines predicted values.

\begin{tabular}{|l|c|c|}
\hline \multicolumn{3}{|c|}{$\begin{array}{c}\text { Table 2. Maximum percentage difference in observed and } \\
\text { predicted breaker index using different definitions of depth. }\end{array}$} \\
\hline $\begin{array}{c}\text { Observed index } \\
\text { depth based on: }\end{array}$ & $\begin{array}{c}\text { Maximum \% difference } \\
\text { (Goda, 2000) }\end{array}$ & $\begin{array}{c}\text { Maximum \% difference } \\
\text { (USACE, 2003) }\end{array}$ \\
\hline Still water level & 98 & 87 \\
\hline Mean water level & 57 & 48 \\
\hline Effective depth & 37 & 27 \\
\hline
\end{tabular}

\section{Revised Breaker Index Model}

A revised breaker index model is therefore proposed which encapsulates the envelope of breaker indices shown within Figure 7 with depth based on still water level. This allows group effects associated with spatial phasing of evolutionary trends and depth variations within the surf zone due to set up and temporal variations associated with group-induced long waves to be incorporated implicitly.

This revision is achieved by modification of the coefficient $A$, used within the Goda (2000) breaker index formula (Eq. 2). Goda (2007) recommends that $A=0.17$ may be used for regular waves and maximum wave height in an irregular wave train and $A=0.12$ for the significant wave height in an irregular wave train. Goda (2007) analysed data sets of several earlier investigations and found $A$ to vary across the surf zone. However the suggested values of $A$ (maximum $=0.2$ ) remain insufficient to encapsulate the current laboratory data. Thus, the expressions Eq. 3 and 4 have been modified to 
capture the envelope of the present data set using 4 group types (Table 1), propagating onto bed sloes between 5:1 and 20:1.

$$
\begin{aligned}
& A_{s}=(-0.24 m+0.17)\left(\frac{d_{s w l}}{H_{s}^{\prime}}\right)^{(-1.65 m-0.42)} \\
& A_{\max }=(-0.12 m+0.25)\left(\frac{d_{s w l}}{H_{s}^{\prime}}\right)^{(-1.65 m-0.35)}
\end{aligned}
$$

Where $A_{\mathrm{s}}$ and $A_{\max }$ are coefficients to be used in Eq. 2 to determine the significant $\left(H_{s}\right)$ and maximum $\left(H_{\max }\right)$ wave heights; $\mathrm{m}$ is beach slope $(0.2 \geq \mathrm{m} \geq 0.05) ; d_{s w l}$ is the depth based on still water level and $H^{\prime}{ }_{S}$ is the offshore (deep water) significant wave height.

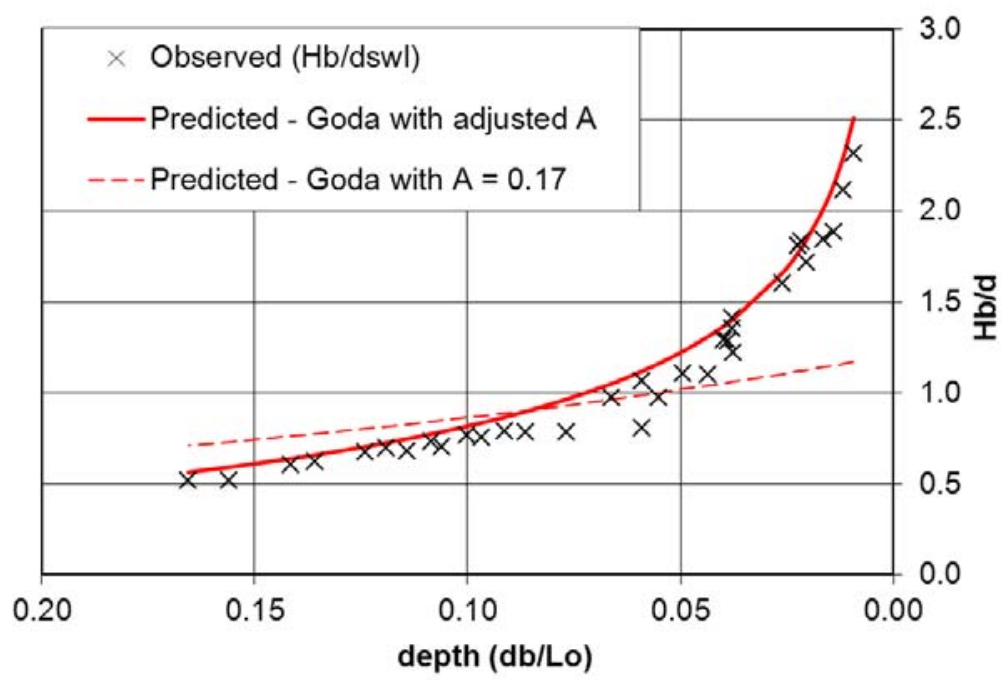

Figure 9. Observed $\mathrm{H}_{b} / d_{s w l}$ for a C2N5r type wave group propagating onto a 10:1 sloped bed compared to values predicted by Goda (2000) (Eq 2) using a fixed and variable coefficient $A$.

Observed breaker indices presented within Figure 7 are compared to the existing Goda prediction of breaker index using $A=0.17$ and to the revised prediction using a variable definition of $A$ according to Eq. 3 (Figure 9). The use of the revised $A$ value can be observed to provide an upper envelope prediction across the entire surf zone. For each of the group type and bed slope combinations tested, the maximum under-prediction of breaking wave height using the existing Goda formula with $A=0.17$ and the variable $A$ are presented within Table 3 . Results show improved agreement across all group type and bed slope combinations tested.

\begin{tabular}{|l|l|c|c|}
\hline $\begin{array}{l}\text { Table 3. Maximum under-prediction of breaking wave height } \\
\text { (\%) using the existing Goda formula with } \boldsymbol{A}=\mathbf{0 . 1 7} \text { and with a } \\
\text { variable coefficient } \boldsymbol{A} .\end{array}$ \\
\hline $\begin{array}{l}\text { Group } \\
\text { Case }\end{array}$ & $\begin{array}{l}\text { Bed } \\
\text { slope }\end{array}$ & $\begin{array}{l}\% \text { diff (Goda w/ } \\
\boldsymbol{A}=0.17)\end{array}$ & $\begin{array}{l}\% \text { diff (Goda w/ } \\
\text { variable } A \text { - Eq. 4) }\end{array}$ \\
\hline C2N5r & $5: 1$ & 40.9 & 1.2 \\
\hline C2N5r & $10: 1$ & 98.2 & 2.1 \\
\hline C2N5r & $20: 1$ & 10.7 & 2.5 \\
\hline C2N3r & $10: 1$ & 38.9 & -0.4 \\
\hline C2N5sb & $10: 1$ & 105.5 & -5.5 \\
\hline C3N5r & $10: 1$ & 36.7 & 1.1 \\
\hline
\end{tabular}




\section{IMPLICATIONS FOR COASTAL STRUCTURAL DESIGN}

The major implications of these findings on the design of coastal structures is that the design wave height decreases more slowly across the surf zone than would be expected according to standard design guides. A desktop assessment of required rock armour for a breakwater extending across the surf zone using wave heights calculated by existing methods, while reliable in the outer surf zone, may under-predict wave height within the inner surf zone in the presence of wave groups, regardless of the definition of depth used (Figure 10). This will ultimately result in a more substantial under-design of armour in this region (e.g. due to Hudson's formula-based designs).

In practice, a number of measures including conservate armour sizing guidelines, design assessment using long duration physical model testing and the tendency for armour rock sized at an offshore position to be continued inshore for some distance, probably limit cases where these discrepancies in wave height could lead to failure. However, the occurrence of low probability large waves within the surf zone have more significant implications for rigid structures such as caisson walls, pipelines, etc. where wave forces which exceed design, could potentially result in catastrophic failure.

In these cases, the possibility of deeper water depths and correspondingly larger waves within the surf zone in the presence of highly grouped wave trains should be considered in preliminary desktop studies rather than only at the physical modelling stage.

A

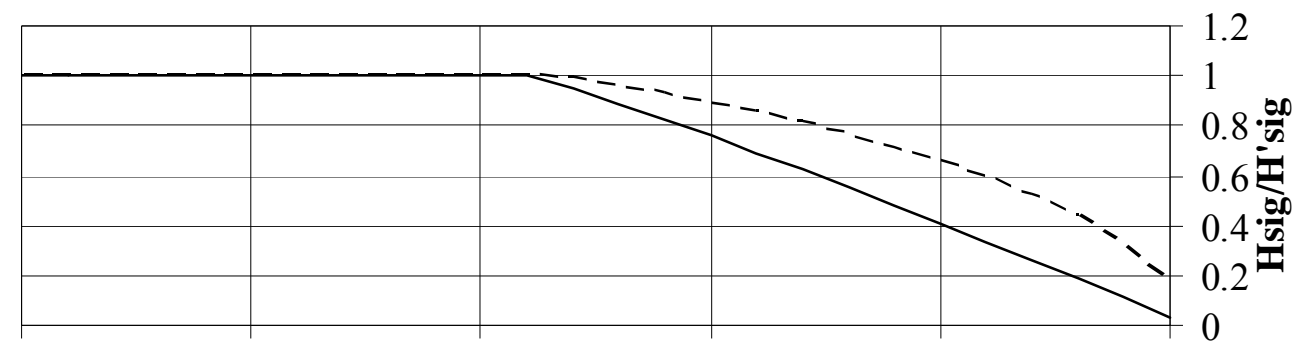

B

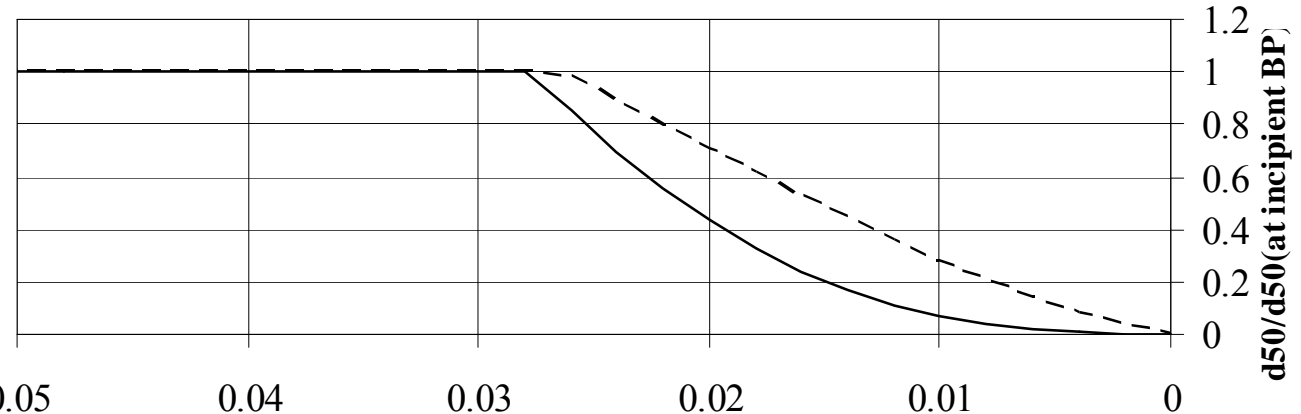

depth (d/Lo)

Figure 10. An example of (A) the change in significant wave height according to Goda (2000) with a fixed coefficient, $A(-)$ and with a modified coefficient $(--)$ and $(B)$, comparison of the nominal diameter $\left(d_{n 50}\right)$ of armour rock as a function of armour rock required at incipient break point $\left(d_{n 50-\text { incipient }}\right)$ using the equations of Hudson (USACE, 2003) based on wave heights with both fixed and varying coefficient $A(-)$ and $(--)$.

\section{CONCLUSIONS AND RECOMMENDATIONS}

Present design guidelines, used to predict the ratio of breaking height to depth for desktop engineering design, are based on investigations which primarily used monochromatic waves, thereby implicitly neglecting group effects. Monochromatic waves are inherently unstable, prompting us to investigate the role of group effects in determining breaker indices. Our results show that it is likely that previously observed scatter is due to the development of wave groups during monochromatic testing.

Wave groups develop with fetch. Consequently, we have investigated the effect of the shoaling fetch relative to group development and its effect on breaker index. Using a depth based on still water level, present design guidelines were found to be conservative within the outer surf zone $\left(\mathrm{d} / \mathrm{L}_{0}>0.05\right)$, but underestimate breaker index by up to approximately a factor of 2 within the inner surf zone $\left.\mathrm{d} / \mathrm{L}_{0}<0.02\right)$. 
Alternative definitions of water depth are possible. These may incorporate a variety of wave setup components and group-induced temporal variations (Longuet-Higgins and Stewart, 1962; Nielsen and Baldock, 2010). However, present guidelines remain non-conservative by factors to 1.2 to 1.6 depending on definition of depth. Presumably, group-related momentum and energy fluxes continue to play a more significant role within the inner surf zone that has been previously anticipated by monochromatic wave testing. The importance of group effects within the inner surf zone appears to become more important as the slope of the offshore bathymetry increases.

A revised method of calculating breaker index across the surf zone has been presented based on the group data obtained during this study. The method revises the coefficient A, used within Goda's breaker index formula (Goda, 2000) from a constant value as is currently used, to vary as a function of bed slope and depth with respect to deep water wave height. This revised formula provided a conservative prediction of breaker index across the surf zone for all bed slopes and group types tested within this present study, regardless of group spatial phasing. More extensive testing of this method is, however, required across a greater variety of bathymetries and wave spectra.

\section{ACKNOWLEDGMENTS}

The authors acknowledge and thank the technical staff at the WRL for their assistance in laboratory testing, particularly Mr John Hart who's presence and advice will be greatly missed. Prof Mike Banner is thanked for his contributions and discussion of wave group processes and Assoc. Prof. Peter Nielsen is similarly thanked for his useful review and comments on infragravity wave development and processes.

\section{REFERENCES}

Baldock, T. E. (2006). Long Wave Generation by the Shoaling and Breaking of Transient Wave Groups on a Beach. Proc. R. Soc. A. 462, 1853-1876.

Baldock, T. E., P. Holmes and D. P. Horn (1997). Low frequency swash motion induced by wave grouping. Coastal Engineering 32: 197-222.

Banner, M. L. and W. L. Peirson (2007). Wave Breaking Onset and Strength for Two-Dimensional Deep Water Waves. J. Fluid Mech. 585: 93-115.

Benjamin, T. B. and J. E. Feir (1967). The disintegration of wave trains on deep water. Part 1: Theory. J. Fluid Mech. 27(3): 417-430.

Goda, Y. (1970). A Synthesis of Breaker Indices. Transactions of JSCE 2(2): 227-230.

Goda, Y. (2000). Random Seas and Design of Maritime Structures. Singapore, World Scientific Publishing Co. Pte. Ltd.

Goda, Y. (2007). Reanalysis of regular and random breaking wave statistics. 54th Japanese Coastal Engineering Conference.

Longuet-Higgins, M. S. and R. W. Stewart (1962). Radiation stress and mass transport in gravity waves, with application to 'surf beats'. J. Fluid Mech. 13: 482-504.

Longuet-Higgins, M. S. and R. W. Stewart (1964). Radiation stress in water waves, a physical discussion with application. Deep-Sea Research 11: 529-563.

Munk, W. H. (1949). Surf beats. Trans. Am. Geophys Union 30: 849-854.

Nielsen, P. and Baldock, T.E. (2010). И-Shaped surf beat understood in terms of transient forced long waves. Coastal Engineering, 57: 71-73.

Ruessink, B. G. (1998). Infragravity Waves in a Dissipative Multiple Bar System. Utrecht University, The Netherlands: 245.

Shand, T. D., W. L. Peirson and R. J. Cox (2008). On the influence of wave groups on shoaling and breaking waves. ICCE 2008, Hamburg, ASCE.

Svendsen, I. A. and J. Veeramony (2001). Wave Breaking in Wave Groups. Journal of Waterway, Port, Coastal and Ocean Engineering July/August, 2001: 200 - 212.

USACE (2003). Coastal Engineering Manual. 1110-2-1100, U.S. Army Corps of Engineers, Washington, D.C. (in 6 volumes).

Weggel, J. R. (1972). Maximum Breaker Height. Journal of the Waterways, Harbours and Coastal Engineering Division 98: 529-548. 